\title{
Registros de incêndios na região metropolitana de Santarém/PA no período de 2012 a 2016
}

A legislação brasileira define incêndios florestais como o fogo não controlado em floresta ou em qualquer outra forma de vegetação. 0 fogo na vegetação acarreta diversos danos, diretos e indiretos, como redução da cobertura do solo, aumento da emissão de carbono e quando este fogo ocorre em áreas urbanas, acarreta um adicional de perigo, por liberar gases nocivos à saúde humana. Teve-se por objetivo, com o presente trabalho, a avaliação quantitativa dos registros de incêndios em formações vegetais na região metropolitana de Santarém, no período de 2012 a 2016. A coleta de dados foi realizada junto ao Centro de Comunicação do 49 Grupamento de Bombeiros de Santarém através do Sistema de Cadastro de Ocorrências de Bombeiros (SISCOB). Para o período de 2012 a 2016, cerca de 2.400 casos de incêndios foram atendidos, tendo a categoria 'fogo na vegetação' apresentado um total de 1.474 ocorrências, com destaque as ocorrências em vegetação do tipo 'mato', com 1.333 casos registrados. O segundo tipo de vegetação mais comprometida no período avaliado foi a 'mata' ou floresta nativa, com 88 ocorrências e, em terceiro, as capoeiras, com 15 ocorrências atendidas. A maior incidência de incêndios na vegetação ocorreu nos meses de setembro, outubro, novembro e dezembro, período que compreende a estação de seca na região.

Palavras-chave: SISCOB; Fogo; Floresta.

\section{Fire records in the metropolitan region of Santarém/PA from 2012 to 2016}

\begin{abstract}
Brazilian law defines forest fires as uncontrolled fire in forests or any other form of vegetation. Fire in vegetation causes several direct and indirect damages, such as reduced land cover, increased carbon emissions, and when this fire occurs in urban areas, it poses an additional danger by releasing gases harmful to human health. The objective of the present work was the quantitative evaluation of fire records in plant formations in the metropolitan region of Santarém, from 2012 to 2016. Data collection was carried out at the Communication Center of the 4th Santarém Fire Brigade Group through the Fire Brigade Registration System (SISCOB). For the period from 2012 to 2016, around 2,400 cases of fire were attended, and the category 'fire in vegetation' presented a total of 1,474 occurrences, highlighting occurrences in 'bush' vegetation, with 1,333 recorded cases. The second most compromised vegetation type in the evaluated period was the 'forest' or native forest, with 88 occurrences, and third, the capoeiras, with 15 occurrences attended. The highest incidence of vegetation fires occurred in September, October, November and December, which includes the dry season in the region.
\end{abstract}

Keywords: SISCOB; Fire; Forest.

Topic: Ciências Florestais

Reviewed anonymously in the process of blind peer.
Received: 05/12/2019

Approved: 10/01/2020
Augusto Campos Lima (iD)

Universidade Federal do Oeste do Pará, Brasil

http://orcid.org/0000-0002-6314-2212

aclima463@hotmail.com

\section{Daniela Pauletto (io}

Universidade Federal do Oeste do Pará, Brasil

http://lattes.cnpq.br/0963317170667125

http://orcid.org/0000-0003-1855-6077

paulettoflorestal@gmail.com

Julio Cesar Galucio de Andrade (ib

Universidade Federal do Oeste do Pará, Brasi

http://lattes.cnpq.br/0691773721217762

http://orcid.org/0000-0003-0700-172X

juliobmgalucio@gmail.com
Jerônimo Monteiro da Silva (D)

Universidade Federal do Oeste do Pará, Brasil

http://lattes.cnpq.br/4628648667206960

http://orcid.org/0000-0003-1542-1986

jeronimomonteirodasilva@gmail.com

\section{Referencing this:}

LIMA, A. C.; PAULETTO, D.; ANDRADE, J. C. G.; SILVA, J. M.. Registros de incêndios na região metropolitana de Santarém/PA no período de 2012 a 2016. Revista Ibero Americana de Ciências Ambientais, v.11, n.1, p.9-18, 2020. DOI: http://doi.org/10.6008/CBPC21796858.2020 .001 .0002 


\section{INTRODUÇÃO}

Incêndios na vegetação geram danos em diversos graus, desde a degradação da vegetação, impactos sobre a biodiversidade, aumento nas emissões de carbono para a atmosfera, acarretando prejuízos financeiros e problemas de saúde, podendo chegar a causar mortes (TORRES et al., 2016). Incêndio florestal pode ser definido como uma combustão sem controle, que se propaga livremente, consumindo os combustíveis naturais preexistentes em uma floresta e respondendo à variação do ambiente, além de influências derivadas dos combustíveis naturais, clima e topologia (FERREIRA et al., 2014). Considerando ainda uma definição prevista na legislação, cita-se o Decreto № 2.661, de 8 de Julho de 1998, que prevê por incêndios florestais o fogo não controlado em floresta ou qualquer outra forma de vegetação (BRASIL, 1998).

Mundialmente, grande parte das ocorrências de incêndios florestais registradas se dá sob combinações ideais de material combustível e condições climáticas e, apesar da adoção de diversas medidas preventivas e protecionistas, os incêndios ainda são potenciais destruidores de grandes áreas florestais ao redor do globo (TETTO et al., 2012). De acordo com os autores, no Brasil, o período mais comum para a ocorrência de incêndios florestais se situa nos meses de junho a novembro, tendo os meses de agosto a setembro, o maior número de registros de ocorrências de incêndio. Neste contexto, o homem é considerado o principal causador de incêndios na vegetação, uma vez que a maioria das ocorrências começa por ação antrópica, ainda que, em menor número, existem aqueles causados por fenômenos naturais.

As principais causas apontadas para estas ocorrências são as práticas agropastoris, onde se destaca a queima para limpeza de terrenos e abertura de novas áreas e, ainda, o uso do fogo para renovação de pastagens e controle fitossanitário. Em geral, podem ser destacadas outras causas antrópicas, tais como: a realização de fogueiras em áreas de visitação pública; incêndios intencionais por atos de vandalismo; e, displicência de fumantes que jogam cigarros ou fósforos acesos na vegetação (MORAIS, 2011). Ainda, segundo o autor, linhas elétricas, sem manutenção, em contato com a vegetação; faíscas provenientes do trilho de estradas de ferro; raios e carvoeiros que não tomam precauções para extinção total e correta do fogo; são causas de ocorrência de fogo na vegetação.

A perícia de incêndios é fundamental como medida preventiva, porém, poucos incêndios são de fato investigados em virtude do baixo grau de danos gerados (GOIÁS, 2017). Em caso de incêndios florestais, a investigação busca identificar situações de riscos e fatos causais da queima, de modo a aplicá-las na definição de medidas preventivas eficazes, sendo importante que a investigação ocorra baseada no concreto, nunca em pressuposições, pois apenas fatos podem nortear a origem do incêndio, suas causas e indícios do autor (PEREIRA et al., 2010).

Os incêndios florestais provocam sérias mudanças no contexto florestal, causando diversos transtornos no cenário político, econômico, social, ecológico e paisagístico, contribuindo ainda para as mudanças climáticas, poluição atmosférica, transformações de ecossistemas e também no surgimento de doenças respiratórias (TEBALDI et al., 2013; LOURENÇO et al., 2012; MORAIS, 2011). 
O Material Particulado Fino (do inglês, Particulate Matter - PM 2,5), proveniente da fumaça decorrente de queimadas, prejudica o bem-estar público, uma vez que gera restrições na visibilidade, agrava a qualidade do ar e reside por um tempo maior na atmosfera, quando comparado às partículas grossas (CARMO et al., 2010). O autor também informa que este material tem a possibilidade de ser transportado por longas distâncias, o que denota alta capacidade de dispersão e de impacto sobre os seres humanos, uma vez que se depositam nos brônquios terminais e nos alvéolos, agravando problemas respiratórios e levando às mortes prematuras.

Além disso, a exposição ao material particulado fino tem efeitos na saúde da população, pois pode causar doenças cardiovasculares (isquemia, arritmia e infarto do miocárdio), principalmente em crianças e idosos, sendo os últimos suscetíveis aos poluentes do ar, havendo uma forte correlação entre o aumento de focos de calor/queimadas e surgimento de doenças respiratórias em idosos (CASTRO et al., 2009).

Na Amazônia, a emissão de partículas finas decorrentes de queimadas representa cerca de $60 \%$ do material particulado conduzido à atmosfera, contribuindo para a alteração da composição química da atmosfera amazônica, com implicações significativas em nível local, regional e global, tendo valores que ultrapassam os limites observados em muitos centros urbanos (CARMO et al., 2010).

Segundo dados do Instituto Nacional de Pesquisas Espaciais (INPE), no ano de 2018, o estado do Pará apresentou 22.080 mil focos ativos, detectados pelo satélite de referência. Até o dia 15 de maio de 2019 já foram registrados 556 focos de incêndios ativos em todo o estado. Em estudo, Torres et al. (2016) ressaltam a importância do uso de dados estatísticos de ocorrências de incêndios florestais como ferramentas na criação de programas de proteção florestal, uma vez que, segundo os autores:

[...] quanto mais se entender sobre o comportamento do fogo e sua resposta às condições ambientais, mais se poderá antecipar situações perigosas, ou impactos de grande magnitude, e mais acertadas serão as decisões sobre a gestão de combustíveis e dos incêndios... todas as regiões, mesmo as mais próximas, têm o seu próprio contexto específico de comportamento do fogo e, portanto, enfatizam a necessidade de estudos das estatísticas de incêndios locais, a fim de compreender melhor as ocorrências, o que leva à medidas mais eficientes na diminuição dos danos causados.

Ao se considerar os registros de ocorrência de incêndios uma importante ferramenta no combate e prevenção de incêndios florestais, objetiva-se, com o presente trabalho, realizar uma avaliação quantitativa dos registros de incêndios em formações vegetais na região metropolitana de Santarém, no período de 2012 a 2016.

\section{MATERIAIS E MÉTODOS}

\section{Caracterização da Área de Estudo}

O estudo foi realizado na Região Metropolitana do município de Santarém, instituída pela lei Complementar Estadual no 079, de 17 de janeiro de 2012, localizada na Região Oeste do Pará e que compreende os municípios de Santarém, Belterra e Mojuí dos Campos (PARÁ, 2012). A Região Metropolitana

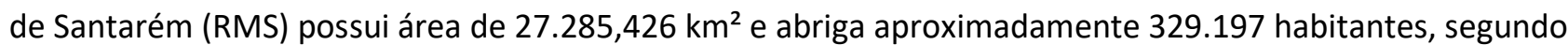
dados de 2017 do Instituto Brasileiro de Geografia e Estatística (IBGE), divulgados no site oficial do município. 
A região RMS (Figura 1) é definida por Gomes et al. (2017) como ambivalente, uma vez que atende ao perfil hegemônico de metrópole, incorporando caracteres típicos de cidades globais como construção de shopping center, pressão por verticalização, loteamentos de luxo; e ainda mantém sua face amazônica, abrigando populações ribeirinhas cuja a subsistência é baseada no rio, comunidades que dependem do uso da terra e que a produção de hortaliças abastecem a cidade; além da preservação da gastronomia típica; e, coexistência na cidade de diferentes identidades culturais e religiosas, como indígenas e quilombolas.

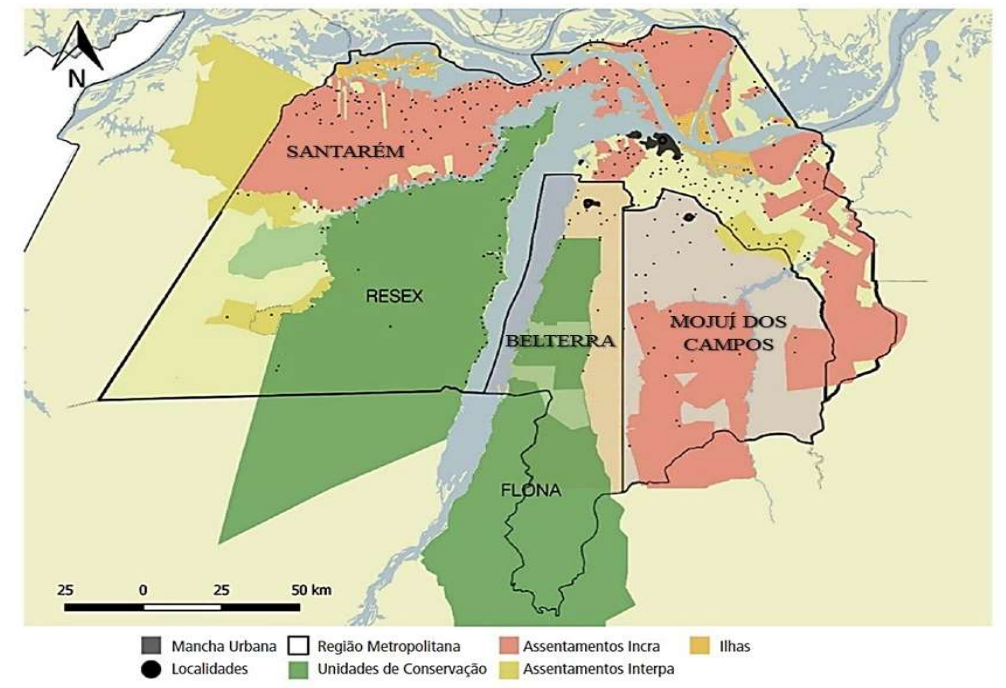

Figura 1: Região Metropolitana de Santarém. Fonte: Adaptado de Gomes et al. (2017).

A localização estratégica de Santarém, no ponto médio entre as capitais Belém e Manaus, justifica a importância que esse município portuário possui desde o período de exploração da borracha (1850 a 1910), até os dias atuais, sustentando um papel de capital regional, sendo referência para as localidades vizinhas em quesitos como urbanização, saúde, educação, comércio, fato que justificou a criação de uma região metropolitana em seu entorno (GOMES et al., 2017).

\section{Procedimento Metodológico}

Para o desenvolvimento deste trabalho, realizou-se a coleta de dados junto ao Centro de Comunicação do 4o Grupamento de Bombeiros de Santarém através do Sistema de Cadastro de Ocorrências de Bombeiros (SISCOB). Este sistema é uma ferramenta que proporciona um conjunto de dados de atendimentos indicando o quantitativo de ocorrências por cidade, bairro ou quartel, além de especificar os tipos de ocorrências. Assim, procedeu-se com a triagem dos registros de fogo em vegetação para composição deste estudo.

Os dados compuseram uma série histórica de cinco anos (2012 a 2016), tabulados em pasta de trabalho no programa Microsoft Exce ${ }^{\circledR}$ versão 2013, sendo utilizadas neste estudo apenas as ocorrências atendidas pelo 4 ㅇ GBM na região metropolitana de Santarém. No SISCOB há a possibilidade de aplicação de diversos filtros, de modo a facilitar a busca por dados específicos, como por exemplo, definição de período de buscas, região (todo o estado do Pará ou município específico), quartel que prestou o atendimento, turno e tipo de ocorrência. Já no caso específico de incêndio, é possível pré-definir em sua busca o tipo de incêndio, 
sendo aplicado nesse estudo o filtro de incêndios por tipo de vegetação. Para a análise estatística, os registros de incêndios na vegetação foram submetidos ao teste de normalidade e, posteriormente, foram analisados pelo teste Tukey, objetivando a comparação de médias. O software utilizado para esse processo foi o Action ${ }^{\circledR}$.

\section{RESULTADOS}

\section{Total de Ocorrências}

Foram registrados pelo SISCOB, para o período de 2012 a 2016, cerca de 2.400 casos de incêndios, distribuídos em diferentes tipos, sendo eles: vegetação, edificação, rede elétrica, entulho/resíduos/lixo, transporte e outros (Figura 2), observando-se que a maior parte dos incêndios (61,4\%) corresponde à ocorrência na vegetação.

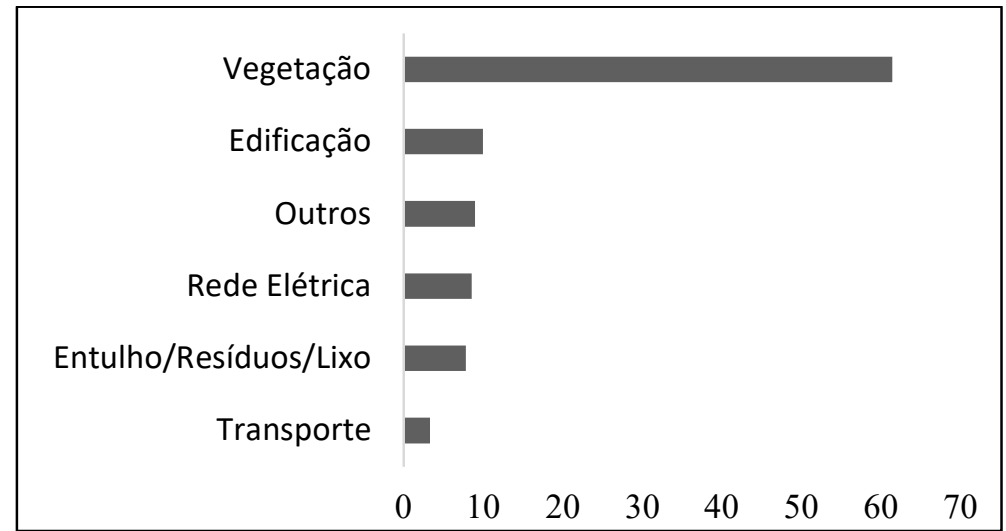

Figura 2: Percentual de registros de incêndios atendidos, em diferentes categorias, no período de 2012 a 2016 , na Região Metropolitana de Santarém.

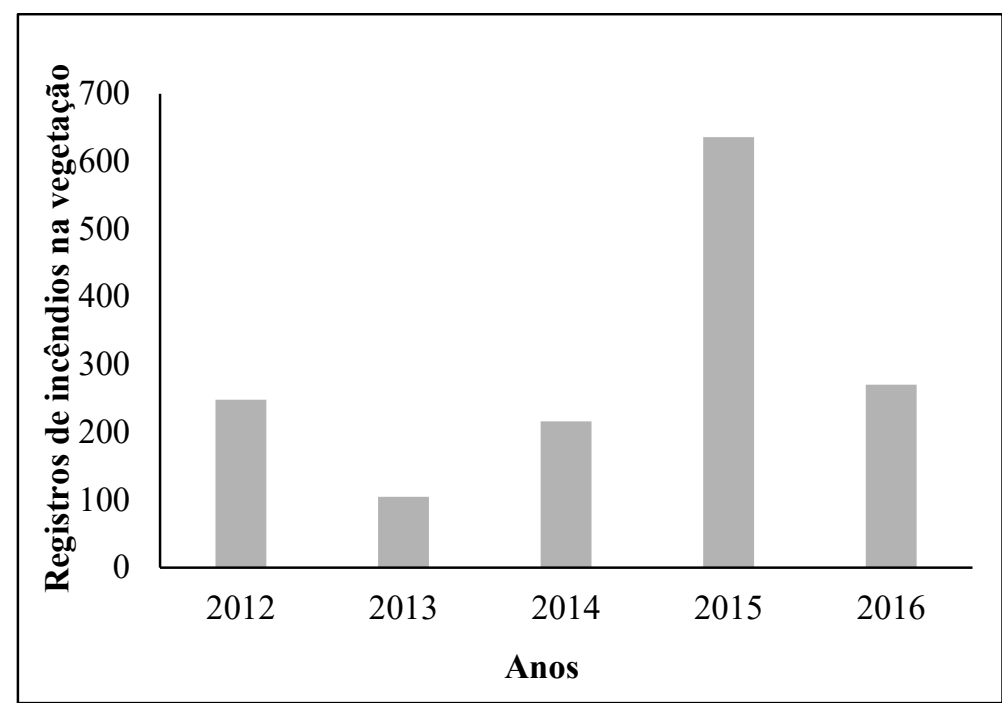

Figura 3: Número de ocorrências de incêndios, registradas no SISCOB, em diferentes tipos de vegetação no período de 2012 a 2016, na Região Metropolitana de Santarém.

A categoria 'outros' é caracterizada de acordo com as premissas do SISCOB, como sendo o surgimento de focos de incêndio em recipientes como lixeiras e através de acidentes domésticos como vazamento de gás e explosão de utensílios domésticos, como panela de pressão. Dos 2.400 casos de incêndios ocorridos no período de 2012 a 2016 na Região Metropolitana de Santarém, 1.474 se enquadraram na categoria 'fogo na vegetação', representando uma média anual de 294,8 ocorrências (Figura 3). 
Analisando-se os registros anuais, nota-se que o ano de 2015 foi o que apresentou maior ocorrência de incêndios florestais, quando comparado aos demais anos da série, um total de 636 casos.

\section{Análise estatística}

A figura 4 demonstra o resultado da análise estatística comparativa para o segundo semestre de todos os anos da série histórica estudada. Esse período, que vai de agosto a dezembro, apresentou o maior número de ocorrências de incêndios na RM Santarém em todos os anos avaliados e é caracterizado como o período em que as médias de precipitação pluviométrica e a umidade relativa do ar são mais baixas, sendo popularmente conhecido na região como estação seca ou verão.

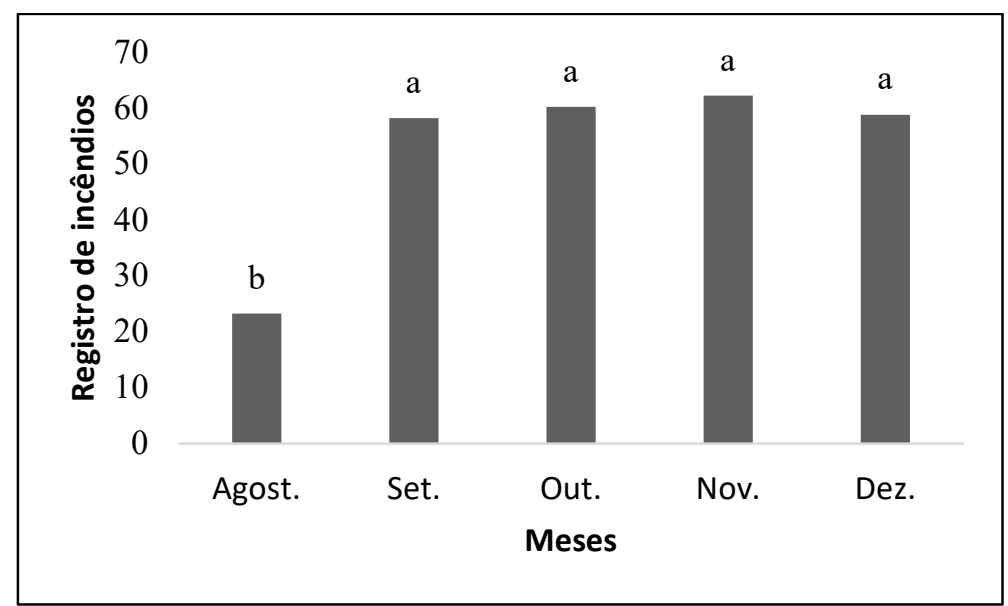

Figura 4: Média mensal dos registros de incêndios ocorrentes nos meses da estação seca registrados no SISCOB, no período de 2012 a 2016, na Região Metropolitana de Santarém.

Com base na análise comparativa do segundo semestre dos anos da série histórica avaliada, foi possível inferir que o mês de agosto apresentou a menor média de registros de incêndios $(23,2 \pm 12,5)$ para todos os anos avaliados, o que difere estatisticamente quando comparado aos meses de setembro, outubro, novembro e dezembro, que apresentaram as maiores médias $(58,2 \pm 39,5 ; 60,2 \pm 32,4 ; 62,2 \pm 58,9 ;$ e 58,8 \pm 72, 4, respectivamente). Estes, por sua vez, foram considerados estatisticamente iguais.

\section{Tipos de vegetação atingida}

Verificou-se que cerca de $90 \%$ dos registros de incêndios ocorreram em áreas definidas como 'mato' (Tabela 1), sendo essa o tipo de vegetação mais afetada durante o período estudado. Em seguida, a vegetação mais comprometida no período foi a 'mata' ou floresta nativa, com 88 ocorrências, o que representa 6,0 \% dos incêndios registrados,

Tabela 1: Acumulado de registro de incêndios em diferentes tipos de vegetação, no período de 2012 a 2016, na Região Metropolitana de Santarém.

\begin{tabular}{|l|l|l|}
\hline \multirow{2}{*}{ Tipo de Vegetação } & Registro de Incêndios \\
\cline { 2 - 3 } & N. & $\mathbf{( \% )}$ \\
\hline Mato & 1333 & 90,4 \\
\hline Mata/Floresta Nativa & 88 & 6,0 \\
\hline Capoeira & 15 & 1,0 \\
\hline Campo & 10 & 0,7 \\
\hline Cultivo Agrícola & 9 & 0,6 \\
\hline
\end{tabular}




\begin{tabular}{|l|l|l|}
\hline Pastagem & 9 & 0,6 \\
\hline Floresta Plantada & 5 & 0,3 \\
\hline Cerrado ou Savana & 4 & 0,3 \\
\hline Caatinga & 1 & 0,1 \\
\hline
\end{tabular}

O terceiro tipo de vegetação mais atingida pelos incêndios foram as capoeiras, com 15 ocorrências registradas, o que representa 1,02\%, sendo as áreas em repouso pelo abandono da agricultura ou áreas em descanso para recuperação da produtividade e que, ciclicamente, retornarão à produção. As vegetações do tipo campo, cultivo agrícola e pastagem registraram juntas 28 ocorrências, o que representam 1,89\% dos registros das ocorrências de incêndios durante o período estudado. Áreas de florestas plantadas, Cerrado ou Savana apresentaram 0,3\% cada uma das ocorrências atendidas. Formações conhecidas como campo, na região metropolitana, apresentaram 10 casos de incêndios e, por último, a vegetação do tipo Caatinga apresentou uma ocorrência no período avaliado.

\section{DISCUSSÃO}

\section{Total de Ocorrências}

Uma importante característica da Região Metropolitana de Santarém é a ausência severa de chuvas durante o verão amazônico. Uma das maiores influências para tais ocorrências é o setor agrícola que vem crescendo potencialmente nos arredores da região, principalmente nos últimos anos devido ao aumento no setor da produção de grãos. Estudos realizados na Amazônia têm identificado anomalias negativas de precipitação no centro, norte e leste da Amazônia, que são diretamente associados com a ocorrência de $E$ I Niño - Oscilação Sul (ENSO) e anomalias de Temperatura da Superfície do Mar (TSM) no Atlântico Tropical Norte (LEWIS et al., 2011).

Molion (1993) mostrou que os meses de outubro e novembro são marcados como meses de seca no estado do Pará e que, nesse período, os processos de chuva estão relacionados com ciclos de curta duração e de grande intensidade, em mesoescala e pequena escala de pluviosidade. A grande concentração de incêndios na vegetação (Figura 2) evidencia o que foi ressaltado no estudo de Torres et al. (2016) sobre o perfil de incêndios florestais em unidades de conservação em um período de 4 anos, onde o mesmo afirma que o uso de práticas de queima está fortemente relacionado ao modo de produção e preparo da terra, sendo a prática de corte-queima utilizada por muitos agricultores, pois as alternativas de menor custo são escassas e despendem maior tempo de execução. Segundo Walker et al. (2009), o modo de preparação da terra para as atividades de pecuária (sobretudo a manutenção de pastos), realizada por meio do método de corte e queima, gera intenso fogo às vegetações suscetíveis, situação agravada pelas atividades de pecuária realizadas na Amazônia por serem de caráter extensivo.

Existem outras fontes de ignição, como corte de madeira, seletivo ou não, que gera clareiras dentro da floresta e, devido à abertura do dossel, a umidade fica muito baixa e a temperatura cada vez mais elevadas no sub-bosque, condições de seca severa, bitucas de cigarro acesas jogadas nas margens de florestas e vegetações, além da direção do vento, que contribui extremamente para ocorrência de incêndios (UHL et al., 1985). 
Em dezembro de 2015, ocorreram incêndios em áreas como a Floresta Nacional do Tapajós em uma Unidade de Produção Anual, onde foram atingidas algumas parcelas em estudo (COSTA et al., 2018). Em estudos realizados por Pismel et al. (2015), a explicação para tal incêndio seria o fenômeno El Niño, responsável pela redução de chuva e caracterizando o período seco, aliado às atividades agrícolas que podem ter colaborado para o aumento de focos de calor na região, fato também observado no ano de 2005 no entorno da Flona Tapajós.

Ainda no segundo semestre de 2015 também ocorreram incêndios no perímetro urbano de Santarém, com destaque para queima de remanescente florestal do Parque da Cidade de Santarém, onde foram atingidas espécies rasteiras e arbóreas, e no Bosque da Vera Paz e área da Empresa Cargill que se caracterizam predominantemente por vegetação rasteira e de rápida combustão (gramíneas).

\section{Análise estatística}

As informações supracitadas corroboram os resultados observados acerca do crescimento de focos de incêndios na região no segundo semestre dos anos. As ocorrências citadas acima foram potencializadas por fatores meteorológicos, pois a umidade relativa do ar associada à temperatura do ar e precipitação pluviométrica, aumentam a facilidade de ocorrerem incêndios e queimadas acidentais e incontroláveis. Logo, é possível afirmar que as condições atmosféricas podem estar propícias ou não a ocorrência de tais situações (OLIVEIRA et al., 2016).

De acordo com Costa (2012), a precipitação anual da cidade de Santarém é de 1.920 mm, ocorrendo maior precipitação entre os meses de dezembro e maio, variando de $170 \mathrm{~mm}$ a $300 \mathrm{~mm}$ como média mensal, conhecida como estação chuvosa ou inverno amazônico, ressaltando-se que esse período chuvoso tem início próximo ao final do mês de dezembro, enquanto os menores índices de precipitação pluviométrica ocorrem entre agosto e novembro, apresentando uma pluviosidade inferior a $60 \mathrm{~mm}$, podendo esse período ser definido como estação seca.

Como visto na Figura 4, não houve diferenças estatísticas para os meses de setembro, outubro, novembro e dezembro quanto à média mensal e desvio padrão dos registros de incêndios, exceto para o mês de agosto que, comparado aos demais, apresentou valores menores. Ressalta-se que, apesar da diferença estatisticamente irrisória, o mês de novembro se destacou dentre como o mês com mais registros de incêndio dentre os meses da estação seca, apresentando um total de 311 ocorrências.

\section{Tipos de vegetação atingida}

A propagação do fogo na vegetação é dinâmica e sofre mudanças abruptas decorrentes da alteração das condições meteorológicas, e nesse caso, os fatores meteorológicos são decisivos na propagação do fogo. A vegetação nativa ou mata nativa em área urbana, seja situada na arborização de vias ou em áreas verdes como praças, bosques ou ainda em camping universitários, é suscetível a degradação por incêndios, sendo essa categoria de vegetação a segunda mais atingida na região metropolitana de Santarém no período avaliado. 
De acordo com o SISCOB, a vegetação do tipo 'mato' mais atingida por incêndios na região metropolitana de Santarém nos períodos avaliados, pode ser definida como vegetação de pequeno a médio porte, não plantada, e, comumente, encontrada em terrenos e locais baldios. A vegetação do tipo 'campo', de acordo com o sistema, é caracterizada por áreas com predominância de vegetação rasteira, herbáceas, normalmente constituídas de gramíneas.

A vegetação do tipo caatinga foi apontada pelo sistema como ocorrente na região, tendo sido registrado um incêndio florestal em área de caatinga, no entanto tal vegetação não é observada no bioma amazônico, sendo esse composto por vegetação do tipo matas de terra firme, matas de várzea e matas de igapó, o que não caracteriza vegetação de caatinga (LINHARES et al., 1998).

\section{CONCLUSÕES}

Os resultados obtidos através deste estudo permitiram concluir as seguintes considerações descritas a seguir. Na série histórica estudada (2012-2016) foi possível observar que o tipo/local mais atingido pelos incêndios foi a vegetação do tipo mato, com 90,4 \% das ocorrências, seguido de mata/floresta nativa, com $6 \%$ dos casos.

O ano de 2015 foi o que apresentou maior número de ocorrências de incêndios, representando 43,2\% dos casos. A maior incidência de incêndios na vegetação ocorreu nos meses de setembro, outubro, novembro e dezembro, devido ao período de seca na região. Faz-se necessário, para melhoria nas ações de prevenção e combate a incêndios florestais, aperfeiçoar o sistema de registro de ocorrências do grupamento (SISCOB) contemplando maior detalhamento da operação como forma de melhorar futuras ações.

Os dados do estudo demonstraram que o abandono de terrenos sem a devida limpeza ou adoção de medidas de prevenção a incêndios consumiu cerca de $90 \%$ dos atendimentos, o que pode haver prejudicado o atendimento de outras demandas evidenciando a necessidade de fiscalização e medidas de participação social na prevenção de incêndios florestais. A formação de brigada envolvendo civis é uma estratégica importante a ser utilizada na região metropolitana de Santarém, devido quantitativo de bombeiros no 4 으 GBM ser insuficiente para o atendimento das demandas de incêndios na região.

\section{REFERÊNCIAS}

BRASIL. Decreto n. 2.661, de 8 de Julho de 1998.

Regulamenta o parágrafo único do art. 27 da Lei no 4.771, de 15 de setembro de 1965 (código florestal), mediante o estabelecimento de normas de precaução relativas ao emprego do fogo em práticas agropastoris e florestais, e dá outras providências. Brasília: DOU, 1998.

CARMO ,C. N.; HACON, S.; LONGO, K. M.; FREITAS, S.; IGNOTTI, E.; PONCE DE LEON, A.. Associação entre material particulado de queimadas e doenças respiratórias na região sul da Amazônia brasileira. Revista Panamericana de Salud Pública, v.27, n.1, p.10-16, 2010.

CASTRO, H. A.; GONÇALVES, K. S.; HACON, S. S.. Tendência da mortalidade por doenças respiratórias em idosos e as queimadas no Estado de Rondônia/Brasil - período entre
1998 e 2005. Ciência \& Saúde Coletiva, Rio de Janeiro, v.14, n.6, p.2083-2090, 2009. DOI: http://dx.doi.org/10.1590/S1413-81232009000600015

GOIÁS. Corpo de Bombeiros Militar. Manual Operacional de Bombeiros: perícia de incêndio. Goiânia: 2017.

COSTA, C. D. F.. Vulnerabilidade ao fogo de florestas intactas e degradadas na região de Santarém-Pará. Dissertação (Mestrado em Ciências Ambientais) Universidade Federal do Pará, Santarém, 2012.

COSTA, M. S. S.; MELO, L. O.. Dinâmica da Regeneração Natural após Manejo e Incêndio em Área da Floresta Nacional do Tapajós. Revista Ibero-Americana de Ciências 
Ambientais, v.9, n.6, p.37-44, 2018. DOI: http://doi.org/10.6008/CBPC2179-6858.2018.006.0004

FERREIRA, C. E. S.; SILVA, J. C. L.; CRUZ, P. R. S.; PASSOS, S. C.. Geografia, gestão e segurança ambiental. Belém: UFPA, 2014.

GOMES, T. D. V.; CARDOSO, A. N. D.; COELHO, H. S.; OLIVEIRA, K. D.. Santarém (PA): um caso de espaço metropolitano sob múltiplas determinações. Cadernos Metrópole, v.19, n.40, p.891-918, 2017. DOI: http://dx.doi.org/10.1590/2236-9996.2017-4009

LINHARES, S.; GEWANDSZNAJDER, F.. Biologia Hoje. 3 ed. São Paulo: Ática, 1998.

LEWIS, S.; BRANDO, P.; PHILLIPS, O.; VAN DER HEIJDEN, G.; NEPSTAD, D.. The 2010 Amazon drougth. Science, v.331, p.554, 2011. DOI: http://doi.org/10.1126/science.1200807

LOURENÇO, L.; FERNANDES, S.; GONÇALVES, A. B.; CASTRO, A; NUNES, A.; VIEIRA, A.. Causas de incêndios florestais em Portugal continental. Análise estatística da investigação efetuada no último quindénio (1996 a 2010). Cadernos de Geografia, Coimbra, v.3, n.31, p.61-80, 2012.

MOLION, L. C. B.. Amazonian rainfall and its variability. In: Hydrology and Water Management in the Humid Tropics, 1993. p.99-111. DOI:

http://doi.org/10.1017/CBO9780511564468.012

MORAIS, J. C. M.. Principais causas dos incêndios florestais e queimadas. Brasília: IBAMA, 2011.

OLIVEIRA, M. C. F.; SOUZA JÚNIOR, J. A.; CRUZ, P. P. N.; SOUZA FILHO, J. D.. Risco de ocorrência de queimada e de incêndio e as medidas de prevenções, em Belém-PA, ano de 2015 (Fire and burning occurrence risk, and contingency measures, in Belém/Pará/Brazil, year of 2015). Revista Brasileira de Geografia Física, v.9, n.4, p.1030-1042, 2016. DOI: http://doi.org/10.26848/rbgf.v9.4.p1030-1042
PARÁ. Lei complementar n.79, de 17 de janeiro de 2012. Estabelece normas de finanças públicas voltadas para a responsabilidade na gestão fiscal e dá outras providências. Belém: DOE, 2012.

PEREIRA, A. M. M.; CATTANEO, A. C. M.; LACERDA, F. S.; MEDEIROS, F. C.; WILMERSDORF, O. R.. Investigação de incêndios florestais. Brasília: IBAMA, 2010.

PISMEL, V. A. M.; MARTORANO, L. G.; ALMEIDA, R. F.; NASCIMENTO, N. C. C.. Focos de calor associados ao efeito do El Nino na Floresta Nacional do Tapajós e seu entorno. In: REUNIÃO ANUAL DA SOCIEDADE BRASILEIRA PARA O PROGRESSO DA CIÊNCIA, 67. Anais. São Paulo: SBPC, 2015.

TEBALDI, A. L. C.; FIEDLER, N. C.; JUVANHOL, R. S.; DIAS, H. M.. Ações de Prevenção e Combate aos Incêndios Florestais nas Unidades de Conservação Estaduais do Espírito Santo. Floresta e Ambiente, Rio de Janeiro, v.20, n.4, p.538-549, 2013. DOI: http://dx.doi.org/10.4322/floram.2013.036

TETTO, A. F.; BATISTA, A. C.; SOARES, R. V.. Ocorrência de incêndios florestais no estado do Paraná, no período de 2005 a 2010. Floresta, Curitiba, v.42, n.2, p.391-398, 2012. DOI: http://dx.doi.org/10.5380/rf.v42i2.22516

TORRES, F. T.; ROQUE, M. P. B.; LIMA, G. S.; COSTA, A. G.; FÉLIX, G. A.; JÚNIOR, M. R. S.. Perfil dos incêndios florestais em unidades de conservação brasileiras no período de 2008 a 2012. Floresta, Curitiba, v.46, n.4, p.532, 2016. DOI: http://dx.doi.org/10.5380/rf.v46i4.44199

UHL, C.; BUSCBACHER, R.. A disturbing synergism between cattle ranch burning practices and selective tree harvesting in the Eastern Amazon. Biotropica, v.17, p.265-268, 1985. DOI: http://doi.org/10.2307/2388588

WALKER, R.; BROWDER, J.; ARIMA, E.; SIMMONS, C.; PEREIRA, R.; CALDAS, M.; SHIROTA, R.; ZEN, S.. Ranching and the new global range: Amazonian in the 21 st. Geafoum. v.40, p.732-745, 2009. DOI: http://doi.org.10.1016/i.geoforum.2008.10.009

A CBPC - Companhia Brasileira de Produção Científica (CNPJ: 11.221.422/0001-03) detém os direitos materiais desta publicação. Os direitos referem-se à publicação do trabalho em qualquer parte do mundo, incluindo os direitos às renovações, expansões e disseminações da contribuição, bem como outros direitos subsidiários. Todos os trabalhos publicados eletronicamente poderão posteriormente ser publicados em coletâneas impressas sob coordenação da Sustenere Publishing, da Companhia Brasileira de Produção Científica e seus parceiros autorizados. Os (as) autores (as) preservam os direitos autorais, mas não têm permissão para a publicação da contribuição em outro meio, impresso ou digital, em português ou em tradução. 